\title{
Qualidade da EduCação E EduCAÇÃo de Qualidade
}

No encerramento de um ano conturbado para o encaminhamento dos temas sociais e educacionais do país, em função de fortes mudanças na realidade sociopolítica nacional e internacional e em meio a processos intermediários de avaliação das publicações científicas e dos programas de pós-graduação realizados pelas autoridades educacionais, EccoS cumpre com sucesso, mas náo sem dificuldades, o projeto de instaurar a periodicidade trimestral e manter a qualidade editorial da revista. Mesmo com significativas mudanças políticas e seus correspondentes impactos em termos de mudanças editoriais, e a decisão de interromper a submissão de novos textos às seção Artigos, o balanço final é bastante positivo: o ano termina com mais de setenta trabalhos publicados; os processos editoriais de revisão cega e por pares mantiveram-se respeitados; o corpo de pareceristas ad hoc integrou pesquisadores espalhados por outras e mais variadas latitudes, o mesmo ocorrendo com as autorias dos textos, em que pesquisadores estrangeiros de tantos outras sedes acadêmicas deram a conhecer suas realidades no campo da pesquisa educacional, ampliando o intercâmbio propiciado pela revista.

De igual maneira, inaugurou-se uma prática que vem se tornando recorrente e benéfica em nome da interação científica entre programas de pós-graduação: a coordenação de dossiês, previamente aprovados pelas instâncias editoriais da revista, a partir de propostas de pesquisadores de outras instituiçóes e outras naçôes, promovendo decisivo intercâmbio institucional, ademais da internacionalização requerida às publicações científicas. É assim que veio à luz o dossiê: "Universidade, Ciência e Tecnologia e Mobilização do Conhecimento” (abr./jun.2019), coordenado por Judith Naidorf, da Universidade de Buenos Aires, em parceria com Ivanise Monfredini, da Universidade Católica de Santos, SP, trazendo o debate acumulado no âmbito do Grupo de Trabalho do Conselho LatinoAmericano de Ciências Sociais de mesmo nome. E é assim que publicamos, neste número, o dossiê: "Educação de Qualidade e Qualidade da Educação", que segue apresentado. 


\section{Dossiê}

Tanto no Brasil quanto em outros países, o tema da qualidade associada à educação tem sido objeto de estudos e pesquisas tendo como foco diversos vieses: avaliação, regulação, supervisão, gestão, dentre outros. Porém, o tema da qualidade da educação - e/ou da educaçáo de qualidade - sempre se faz com base em uma de duas linhas: uma concepção de qualidade total de cunho empresarial-economicista e neoliberal, outra denominada qualidade social, orientada por uma lógica contra-hegemônica ao desenvolvimento excludente perpetrado pelo capital. (COSTA; SILVA, 2015)

Destaca-se que, no cenário comercial e no campo econômico, o conceito de qualidade faz uso de parâmetros de comparabilidade, medidas e níveis mensuráveis, padróes, rankings, testes e estandardizaçáo próprias do âmbito mercantil (SILVA, 2009). Por sua vez, a qualidade social fundamenta-se em práticas de políticas democráticas, de responsabilidade do Estado e de participação representativa e significativa da comunidade nos processos de tomada de decisão e de controle social. Não se restringe a fórmulas matemáticas nem a medidas lineares, analisada que é no contexto de aspectos intra e extra institucionais. (DOURADO; OLIVEIRA, 2009; SILVA, 2010)

Diante desse quadro, que impóe desafios importantes às políticas, práticas e avaliações no campo da educação, no país e fora dele, as coordenadoras deste dossiê propuseram a EccoS o debate da temática que relaciona Qualidade e Educação no sentido de se avançar em relação às linhas antes mencionadas, buscando contribuiçóes de pesquisadores brasileiros, de Espanha e de Portugal. De partida, a proposta vale-se de pesquisas desenvolvidas pelas professoras Daniela da Costa Britto Pereira Lima, da Universidade Federal de Goiás, e Kátia Morosov Alonso, da Universidade Federal do Mato Grosso, que contaram com o apoio da Coordenação de Aperfeiçoamento de Pessoal de Nível Superior (Capes), da Fundação de Amparo à Pesquisa do Estado de Goiás (Fapeg) e do Conselho Nacional de Desenvolvimento Científico e Tecnológico (CNPq); de mesmo modo, orientam-se pelos resultados acadêmicos das investigaçóes levadas a efeito pelo Grupo de Pesquisa: Políticas, Avaliação e Gestão, da Universidade Cidade de São Paulo (Unicid), representado neste dossiê pela Profa. Célia Haas. As três professoras constituíram o grupo coordenador da seção Dossiê Temático nominado "Qualidade da Educação e Educação de Qualidade”. 
Os estudos e pesquisas que aqui se apresentam, na forma de artigos vazados em pesquisa empírica e ensaios de contribuição teórica, indicam os diferentes movimentos e dinâmicas que se desenvolvem em relação ao tema, pontuando uma perspectiva crítica em que a educação é vista como prática, direito social e ato político (FREIRE, 1987). Num olhar mais generalista, podemos vislumbrar as diversas temáticas apresentadas no nosso dossiê na nuvem de palavras que representa a amplitude dos estudos publicados e seus viéses:

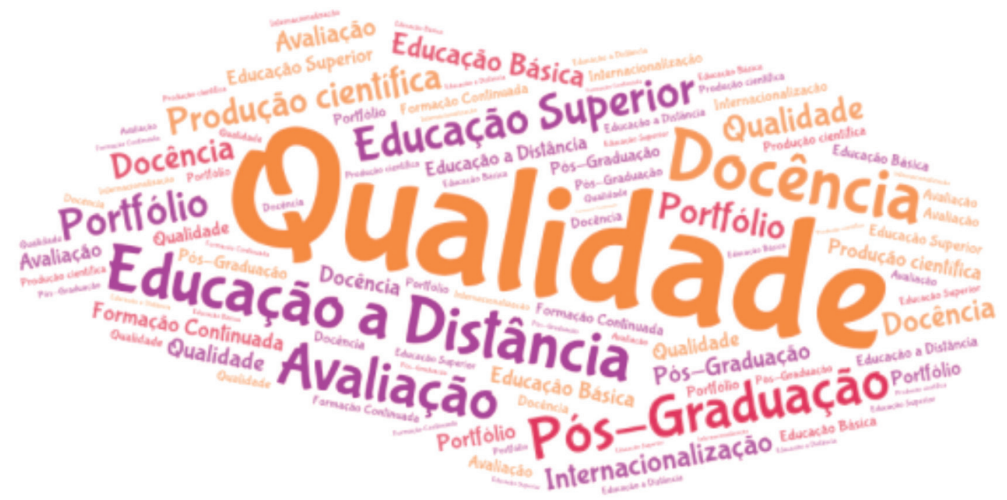

Figura: Nuvem de palavras recorrentes nos trabalhos do dossiê Fonte: Elaborado pelas organizadoras.

De forma mais detalhada, nosso dossiê contempla essas temáticas nos trabalhos que apresentamos a seguir. $\mathrm{O}$ artigo de Luísa Cerdeira, Belmiro Gil Cabrito e Pedro Ribeiro Mucharreira, intitulado O crescimento do ensino superior no Portugal democrático: evolução da pós-graduação e da produçáo científica, apresenta dados oficiais de Portugal e de organismos multilaterais para analisar a expansão da pós-graduação e da produção científica no país, contribuir com elementos importantes para identificar a qualidade tendencial e futura da educação lusitana.

No artigo Qualidade e educação a distância: do referencial teórico à sua proposição, Daniela da Costa Britto Pereira Lima e Kátia Morosov Alonso apresentam denso levantamento bibliográfico nacional e internacional que trata de referencial teórico sobre a qualidade social da educação 
a distância, propondo dimensóes e indicadores para as instituiçóes de educação superior que desenvolvem cursos nessa modalidade.

Em contribuição à temática da qualidade da pós-graduação brasileira, Altair Alberto Fávero, Evandro Consaltér e Carina Tonieto, no artigo $A$ avaliação da pós-graduação e a sua relação com a produção científica: dilemas entre a qualidade e a quantidade, aprofundam a discussão sobre o produtivismo e a performatividade que frequentam tanto a avaliação quanto a expansão dos cursos stricto sensu no Brasil, denunciando o mercado editorial predatório que se instalou na disputa por publicaçóes de professores e pós-graduandos, consideradas as publicações 'qualizadas' como critério fundamental na avaliação dos programas de pós-graduação.

Anabel Galán-Mañas nos apresenta, em La carpeta docente. Instrumento para La evaluación de calidad docente, a importância do portfólio docente como ferramenta de avaliação do professor universitário, dado que possibilita refletir sobre a qualidade do processo ensino-aprendizagem, além de constituir processo de autorregulação do professor que o utiliza e desenvolve e promover melhorias desse processo.

Em seguida, o estudo Avaliação, regulação e qualidade na educação superior: os desafios da gestão acadêmica, de Célia Maria Hass e Ana Silvia Moço Aparício, propóe discussão sobre o posicionamento dos gestores frente aos processos de avaliação estabelecidos pelo Sinaes, apresentando problematizaçóes significativas diante das ressonâncias que os processos avaliativos implicam no cotidiano das instituições pesquisadas.

Mário Azevedo e João Ferreira de Oliveira, no trabalho Internacionalização da educação superior e avaliação da qualidade da pósgraduação: riscos e perspectivas no Brasil e no Reino Unido, analisam as políticas de avaliação e internacionalização da pós-graduação, denunciando a indução à mercadorização e transnacionalização da educação superior em registro comparativo nesses dois países.

O estudo de Maria Manuela Esteves e Regina Magna Bonifácio de Araújo, com o artigo $A$ formação continuada de professores e a elevação da qualidade da educação básica, realiza uma reflexão sobre a formação continuada tendo como foco as realidades de Brasil e Portugal. Como afirmado pelas autoras, mesmo distantes, ambos os países "trazem proximidades e singularidades" em termos de suas reformas educacionais recentes, as 
quais, ao fim e ao cabo, influenciam a formação e o desenvolvimento profissional docente, tema central do estudo.

De Portugal, os colegas Séfora Silva, José António Moreira e Luís Alcoforado, por meio do artigo Educação digital no ensino superior em Portugal em contexto de reclusão: o campus virtual Educonline@pris, avaliam, por meio de análise qualitativa, potencialidades e limitações do funcionamento desse campus, o que contribui para visualizar a qualidade ou não dessa oferta e os elementos nela imbricados.

$\mathrm{O}$ artigo Qualidade regional revelada pelo Sistema de Acreditação de Cursos Universitários do MERCOSUL, de Marianne Pereira de Souza e Giselle Cristina Martins Real, discute a concepção de qualidade revelada no primeiro ciclo desse sistema, demonstrando seu caráter competitivo e sua influência no cumprimento de critérios de nível regional.

Marco Wandercil, Adolfo-Ignacio Calderón e Francisco Aníbal Ganga- Contreras analisam, no estudo Qualidade da educação superior no Brasil: desempenho das universidades católicas à luz dos rankings acadêmicos, indices e tabelas classificatórias estatais e do setor privado, as tendências em termos de qualidade institucional que se evidenciam nas universidades católicas brasileiras.

Por fim, o artigo Ciclo profissional da docência universitária: percepçôes sobre qualidade incorporada pelo capital cultural, de autoria de Bruna Telmo Alvarenga, Gionara Tauchen e Sirlei Nádia Schirmer, traz como propósito compreender as experiências profissionais construídas ao longo do ciclo de desenvolvimento profissional docente e seus efeitos no (des)investimento na carreira universitária. Indica as formas em que se dá a aquisição de capital cultural (incorporado, objetivado e institucionalizado) na qualificação da docência universitária e os impactos gerados na qualidade das aprendizagens da docência nas demais etapas do ciclo de vida profissional.

Com este dossiê esperamos trazer efetiva contribuição ao debate teórico-prático da qualidade da educação e da construção de uma educação de qualidade, temas caros nos dias atuais em razão de formulaçôes náo científicas que têm invadido os contextos social e político do país, com óbvios impactos nas políticas e sistemas educacionais. Desejamos ótima leitura a tod@s, no ensejo de que a educaçáo seja sempre teorizada e praticada como elemento da emancipação e do desenvolvimento social e, assim, avaliada por sua qualidade socialmente requerida. 


\section{Organizadoras}

\section{Daniela da Costa Britto Pereira Lima}

Doutora em Políticas Públicas, Estratégias e Desenvolvimento pela Universidade Federal do Rio de Janeiro. Professora da Universidade Federal de Goiás. Editora Chefe da Revista UFG. Líder do Grupo de Pesquisa em Tecnologias e Educação a Distância (GEaD/UFG/DGP-CNPq).

ORCID: https://orcid.org/0000-0002-1075-2113

daniela_lima@ufg.br.

Kátia Morosov Alonso

Doutora em Educaçáo pela Universidade Estadual de Campinas. Professora da Universidade

Federal de Mato Grosso. Líder do Grupo de Pesquisa Laboratório de Estudos Sobre Tecnologias da Informação e Comunicação na Educação (LêTECE/UFMT/DGP-CNPq.

ORCID: https://orcid.org/0000-0002-7125-664X katia.ufmt@gmail.com.

\section{Celia Maria Haas}

Doutora em Educaçáo (Supervisão e Currículo) pela Pontifícia Universidade Católica de São Paulo. Professora do Programa de Mestrado em Educaçáo da Universidade Cidade de São Paulo. Editora da Revista @mbienteeducação. ORCID: http://orcid.org/0000-0002-8462-8350

celiahaas1@gmail.com

\section{Editores}

\section{Eduardo Santos e Manuel Tavares}

\section{Referências}

COSTA, N. M. De L.; SILVA, A. M. C. e. Qualidade social e políticas para a Educação Superior no Brasil. Revista de Estúdios e Investigación en Psicologia y Educación, 2015, v. Extr., n. 12. Disponível em: https://www.researchgate.net/ publication/287972167_Qualidade_social_e_politicas_para_a_Educacao_ Superior_no_Brasil. Acesso em: 10 jul. 2019.

DIAS SOBRINHO, J. Democratização, qualidade e Crise da Educação Superior: faces da exclusão e Limites da Inclusão. Revista Educação e Sociedade, Campinas, SP, v. 31, n. 113, p. 1223-1245, 2010.

DOURADO, L. F.; OLIVEIRA, J. F. de. A qualidade da educação: perspectivas e desafios. Cad. Cedes, Campinas, SP, v. 29, n. 78, p. 201-215, 2009.

FREIRE, Paulo. Pedagogia do oprimido. 37. ed. Rio de Janeiro: Paz e Terra, 1987.

SILVA, M. A. da. Qualidade social da educação pública: algumas aproximações. Cad. Cedes, v. 29, n. 78, p. 216-226, 2009. Disponível em: http://www.scielo.br/scielo. php?script=sci_arttext $\&$ pid=S0101-32622009000200005. Acesso em: 10 jul. 2019. 